\title{
A RELAÇÃO ENTRE SAÚdE E TRABALHO DO PONTO DE VISTA BIOÉTICO ${ }^{(*)}$
}

\author{
Giovanni Berlinguer(**)
}

\section{INTRODUÇÃO}

A relação entre o trabalho e a saúde se coloca na interface entre a biologia humana e a economia, isto é, entre dois campos nos quais se manifesta um crescente interesse pela ética.

No campo biológico, na onda deste interesse, nasceu uma nova disciplina, a bioética, como era previsível devido aos extraordinários mas também perturbadores progressos da ciência biomédica. No entanto, era pouco previsível que Mr. John Shad, presidente da SEC, o órgão de controle dos mercados financeiros americanos, doasse trinta milhōes de dólares para a Harvard Business School criar uma nova disciplina no ensino: Ética e negócios. G. Rossi, que é o homólogo italiano a Mr. Shad, escreveu no "Corriere della Sera", jornal que pertence à Fiat: "O problema da relação entre a ética e a atividade econômica sempre esteve no centro das mais angustiantes reflexões do pensamento antigo e moderno. Isto torna-se atual cada vez que se apresentam períodos de crise ou de transformaçāo...Conclamar à ética é sinal de que no mundo da economia ocidental o direito apresenta problemas ou está em crise, e que portanto estão amadurecidos os tempos para reformas radicais no ordenamento" ${ }^{1}$. Se isto é

(*) Tradução do original italiano: MARINA PEDUZZI, Enfermeira do CSE Samuel Pessoa (Butantā, FMUSP); Mestre em Enfermagem de Saúde Pública (EERP-USP). Revisão Técnica: José da Rocha Carvalheiro (Editor).

(**) Professor da Universidade "LA SAPIENZA", Roma; Professor visitante do IEA-USP,em 1993. Financiamento : FAPESP 
verdadeiro para a economia ocidental,é mais verdadeiro ainda para o resto do mundo, que é influenciado por esta.

Os princípios morais que dizem respeito à relação entre trabalho humano, economia e saúde têm tido nos últimos decênios definições mais claras, precisas e respeitáveis. Me refiro, como exemplo, a três textos de fontes diferentes.

Um texto é a Encíclica Pacem in terris, editada exatamente há trinta anos (11 de abril de 1.963) pelo papa João XXIII. O capítulo Direitos atinentes ao mundo econômico começa com estes dois pontos:

"17. Aos seres humanos é inerente o direito da livre iniciativa no campo econômico e o direito ao trabalho.

18. Estes direitos estão indissoluvelmente conjugados ao direito às condiçōes adequadas de trabalho que não sejam lesivas para a saúde física e inadequadas aos bons costumes, e que não sejam obstáculos para o desenvolvimento integral dos seres humanos em formação; e, no que diz respeito às mulheres, o direito a condições de trabalho conciliáveis com a sua condição e com seus deveres de esposa e mãe".

O outro texto é a Declaration on Worker's Health, editada em Washington em 6 de fevereiro de 1.992, por importantes personalidades do mundo da economia, da política e da ciência, reunidas por iniciativa da Organização Panamericana de Saúde no ano que a OPS dedicou à segurança e à higiene no trabalho. Após ter enfatizado "the high cost of disabilities and lost lives resulting from work-related pathologies, unhealthy working conditions, and serious occupational risk factors which could be eliminated and controlled", a declaração enfatizou dois aspectos éticos da relação entre trabalho e saúde: 
"The aims of the economic progress are only justified to the extent that concern is focused on human beings and their social well-being, and that in order to ensure viable and sustained development it is essential that workers enjoy good levels of health".

"Knowledge is available about the strategies and techniques for eliminating, reducing, and controlling occupational risk factors; the application of this knowledge is not only beneficial for workers, but also leads to the attainment of a more equitable, stable, and productive society".

O último documento diz respeito diretamente àqueles que se ocupam do problema como profissionais. Em 1.992 a International Commission on Occupational Health (ICOH) publicou, após amplas consultas, um International Code of Ethics for Occupational Health Professionals, que consta de 26 parágrafos. $\mathrm{O} I \mathrm{COH}$ resumiu o conteúdo dessa publicação em três pontos:

1. Occupational health practice must be performed according to highest professional standards and ethical principles. Occupational health professionals must serve the health and social wellbeing of the workers, individually and collectively. They also contribute to environmental and community health.

2. The obligations of occupational health professionals include protecting the life and the health of workers, respecting human dignity and promoting the highest ethical principles in occupational health policies and programmes.

Integrity in professional conduct, impartiality and the protection of the 
confidentiality of health data and of the privacy of the workers are part of these obligations.

3. Occupational health professionals are experts who must enjoy full professional independence in the execution of their functions. They must acquire and mantain the competence necessary for their duties, and require conditions which allow them to carry out their tasks according to good practice and professional ethics.

As orientações que emergem destas citaçōes parecem claras e lineares. Parecem. Entre parecer e ser encontramos porém duas dificuldades, que resumirei brevemente ainda que depois desenvolva neste texto somente a primeira.

A primeira, está no fato de que os desenvolvimentos da ciência, as regras do mercado, as leis civis e penais, as normas deontológicas das profissōes da área da saúde não têm fornecido respostas atualizadas aos problemas éticos que se manifestam em muitos aspectos do trabalho moderno. Falo sobretudo dos conflitos entre valores e interesses diferentes, nenhum dos quais pode anular o outro; no entanto, cada um destes pode pretender, em algum grau, uma justificativa ética própria. Refiro-me em particular aos seguintes pontos, cada um dos quais se desdobrará num capítulo deste trabalho: 1) o conflito entre o direito à vida, à saúde e à segurança dos trabalhadores e o direito das empresas a maximizar a produção ; 2) o conflito que se refere à informação: direito dos trabalhadores a conhecerem os riscos, direito da empresa aos segredos industrial e comercial, direitos e deveres dos "experts" profissionais; 3) o conflito entre a produção e o ambiente externo, entre trabalhadores e população; 4) Os conflitos internos entre trabalhadores; 5) Os conflitos entre trabalho, saúde reprodutiva e reprodução da vida. 
Outra dificuldade é que, enquanto tentamos aprofundar temas da bioética que pertencem ao presente técnico-científico, em alguns casos mais ao futuro que ao presente, vemos com angústia que em muitos países não somente permanece mas em alguns casos se amplia o tipo de exploração mais antigo e inumano. Falo da escravidão e da servidão, isto é, de praticas de trabalho moralmente superadas há séculos e declaradas ilegais desde a Slavery Convention de 1926, promulgada pela League of Nations. O World Labour Report de $1993^{2}$ dedica o primeiro capítulo a uma alarmante descrição das varias formas de forced labour hoje existentes: a escravidão tradicional (Mauritânia e Sudão); o bonded labour, no qual o trabalhador está vinculado por toda a sua vida à empresa, devido a dívidas que não pode pagar (Paquistão, India, Peru); o trabalho forçado de pessoas que são arrancadas, transferidas do seu local de origem e mantidas trabalhando sob ameaça de armas (Brasil, República Dominicana); o corvèes do tipo comunitário, e o fornecimento de presidiários como mão de obra para empresas privadas, e o trabalho servil de menores. O Report não fala de outros tipos de constrangimento, como aqueles a que estão submetidos os trabalhadores imigrantes em países desenvolvidos (incluída a Itália). De qualquer maneira o quadro é impressionante, e justifica a afirmação inicial do Report: "At the end of the twentieth century many people assume that slavery has been eradicated. Unfortunately not"

Quero assinalar que, ao preparar este ensaio, consultei uma ampla literatura na área de bioética a respeito do unitermo "trabalho humano" sem encontrar um só artigo que se referisse ao problema, já percebido há muito tempo, ora documentado neste Report. Isto confirma que existe, nesta disciplina, uma profunda deformação cultural ${ }^{3}$. Esta consiste no fato que a atençāo se concentra nos temas que dizem respeito às fronteiras mais avançadas da ciência nos países desenvolvidos, enquanto se descuidam implicações morais ( que dizem respeito a cada um dos 
cidadãos do mundo) da vida cotidiana nos territórios, nas classes sociais e nas pessoas que têm certamente o maior sofrimento.

Eu mesmo me dou conta de que aquilo que direi incorpora em alguma medida esta mesma distorção.

\section{CONFLITO ENTRE TRABALHADORES E EMPRESA}

Sempre existiu um conflito entre as exigências de saúde e de segurança dos trabalhadores e a tendência das empresas para maximizar a produção com o mínimo de gastos. Este conflito mudou de formato nas várias épocas e nas várias sociedades e foi uma ilusão pensar que isto diminuiria quando a propriedade privada da empresa foi substituída pela propriedade pública. A relação entre estes valores e interesses, às vezes coincidentes porém mais freqüentemente contraditórios, somente foi regulamentada com base em três fatores: isto é, foi definida de uma forma brutal,mas bastante realística, como "relação de força" entre as partes sociais; as leis do estado; e os princípios éticos. Estes últimos podem inclusive assumir uma forma de antítese, como aparece em duas formulações típicas. Uma está no próprio título de um famoso artigo de $M$. Friedman: The social responsability of business is to increase its profits. ${ }^{4}$ A outra, na já citada declaração da OPS: "The aims of economic progress are only justified to the extent that concern is focused on human beings".

Me deterei sobretudo no fato que, ao regulamentar a relação entre os trabalhadores e a empresa, além dos três fatores que já foram elencados (relaçōes de força, leis, ética), influencia também um quarto fator: o conhecimento científico, as sua implicações técnicas, as orientações dos profissionais. Muitas das decisōes, que antes 
eram tomadas baseadas em julgamentos empíricos, passam agora a ser julgadas através deste valor.

Um exemplo típico é a seleção de trabalhadores no momento da admissão e, depois, nas avaliações periódicas. A admissão acontecia no passado ad nutum, com um aceno de mão do chefe o qual julgava e escolhia os mais idôneos e os mais adequados para o cumprimento da tarefa que seria desenvolvida. Depois foi introduzida a consulta médica, os testes de comportamento, e, sucessivamente, screening mais complexos que envolvem a genética, a identificação das pessoas hipersensíveis a determinados riscos, a medicina preventiva, o monitoramento biológico dos trabalhadores, a avaliação das condições de comportamento extra trabalho que podem causar maior morbidade e maior ausência no trabalho (obesidade, fumo, pouca atividade físico-esportiva).

No plano da ética emergem dois problemas: a tutela da privacidade dos trabalhadores, e a relação entre o sujeito e o ambiente na prevenção dos riscos profissionais. A violação da " privacidade genética" pode se tornar muito perigosa.

Escreveu a este respeito S. Rodotá: "Vivemos em um tempo no qual, a cada momento, parecem se bloquear os mecanismos de aceitação daquilo que parece diferente e diverso. Mas as velhas formas de discriminação e de estigmatização, aquelas que faziam com que se investisse contra drogados, homossexuais, comunistas, correm o risco de se tornarem pouca coisa frente à grande ênfase na diversidade genética. Para aqueles que recebiam este tipo de acusação odiosa, permanecia uma possibilidade de defesa: na desintoxicação, na abstinência sexual e na possibilidade de se retratar ideologicamente. Esta possibilidade é perdida frente a uma diversidade genética que foge ao domínio da vontade individual, que constituí a estrutura profunda da pessoa, que na realidade se configura como um destino e não 
como uma escolha. Assim, o veredicto corre o risco, no caso, de ser definitivo" 5 . Pode-se acrescentar, citando uma observação de Harris, que também no plano subjetivo é provável "que os trabalhadores identificados como de risco fiquem angustiados pela sua condição e pelas conseqüências, que derivam desta condição, e que esta situação de angústia continue talvez pelo resto de sua vida, que pode revelar-se uma vida longa e sadia". 6

Uma pesquisa realizada pelo governo nos Estados Unidos mostrou que $75 \%$ das Empresas começaram ou pretendem começar programas de screening genético dos trabalhadores, ${ }^{7}$ ainda que pelo estímulo das companhias de seguros, as quais exigem, nas apólices contratadas com a empresa, uma seleção preliminar do seu pessoal. Portanto, é provável que esta tendência se estenda a outros países. A justificativa moral é que, desta maneira, se eliminam aqueles candidatos a trabalhador que, admitidos pela empresa, encontrando-se na presença de substâncias químicas às quais sejam hipersensíveis, correriam risco mais elevado. Isto pode ser verdadeiro e necessário, mas podemos fazer algumas objeçōes: 1) que, de fato, os casos de hipersensibilidade genética são extremamente raros; 2 ) que aqueles que são excluídos do trabalho com base neste tipo de "screenig", correm um maior risco de permanecerem desempregados e, portanto, de adoecerem devido a esta condição; 3) que, se este sistema se generalizasse, somente as pessoas super resistentes poderiam ser admitidas no trabalho; nem mesmo Superman, provavelmente porque (se bem me recordo) ele era geneticamente vulnerável à cryptonita; 4) que screening na admissão, baseados não na adequação ao trabalho, como é legítimo, mas na maior resistência aos fatores nocivos presentes no ambiente, podem ser considerados ou tornar-se substitutivos de medidas de prevenção primária e, portanto, constituírem obstáculo para a efetiva introdução desta: na prática "a possibilidade de escolher os empregados e trabalhadores com base no risco pode diminuir a obrigaçāo de tornar 
- ambiente físico de trabalho seguro e saudável, tornando assim o mundo em geral um lugar mais perigoso e desagradável". 8

Deterei-me também em outras antinomias que se apresentam neste campo: mercantilização do risco versus transformaçōes produtivas, promoção da saúde versus controle dos comportamentos, risco versus benefício.

A respeito da primeira antinomia existe na Itália uma ampla experiência porque, por um longo tempo, até a metade dos anos sessenta as empresas ofereciam (e os sindicatos pediam) aumento de salário como compensação monetária para os riscos e a insalubridade no trabalho. Uma das conseqüências foi que, não existindo nenhum estímulo para a prevenção, o número de acidentes cresceu de uma média de 171 casos por mil operários por ano, no período de 1.951 a 1.955, até o máximo de 231 casos no ano de 1.963; uma tendência análoga de aumento foi verificada nas doenças profissionais. Somente então as organizações sindicais iniciaram um movimento que tinha como motivação ético-política a afirmação que "a saúde não se vende", e, como objetivo contratual, modificar o ambiente e a organização do trabalho de modo a torná-los mais saudáveis e mais seguros. ${ }^{9} \mathrm{Em}$ termos concretos o movimento, que se desenvolveu com vigor por cerca de 15 anos, obteve três resultados: os acidentes $e$ as doenças profissionais foram reduzidos de um terço, $e$ as mortes por estas mesmas causas se reduziram à metade; as leis incorporaram os direitos dos trabalhadores a conhecer e controlar o ambiente produtivo; a inovação tecnológica foi estimulada e a atividade industrial obteve vantagens com isto.

Algumas destas experiências (que nos anos 80 foram ofuscadas, resultando no retorno à "monetarização" do risco e também numa tendência recente de aumento no número de acientes e doenças) tiveram eco também em outros países. O movimento sindical no Brasil, por exemplo, apresentou reivindicações análogas, que 
foram atendidas em alguma medida, até no que diz respeito às normas governamentais, entre as quais o dispositivo número 5 do Departamento Nacional de Segurança e Saúde do Trabalhador, de 17 agosto de 1.992, que estabelece para as empresas, a obrigação de elaborarem "mapas de risco" e de torná-los conhecidos por todos os trabalhadores.

Descrevi brevemente os efeitos práticos deste movimento, porém devemos aqui resumir os seus significados éticos: a) a prioridade do valor da vida e da saúde, por referência à recompensa monetária pela sua perda; b) tornar realidade, por iniciativa dos trabalhadores, o princípio moral (por exemplo, retomado no artigo $41 \mathrm{da}$ Constituição Italiana) segundo o qual a atividade econômica "não pode desenvolver-se contrária à utilidade social ou de modo a criar danos, prejuízos para a segurança, para a liberdade e para a dignidade humana"; c) a passagem dos trabalhadores da "consciência de explorado", ou de "vendedor da força de trabalho", para a "consciência de produtor", consciente de ser sujeito conhecedor e inovador do progresso tecnológico; d) a construção de um modelo de controle das condições ambientais "de baixo", que parte da experiência de trabalho, das condições ambientais e que ponha no centro: como objetivo a saúde e a vida, e como método a comunicação o intercâmbio entre o universo cognitivo dos trabalhadores e aquele dos experts profissionais ( técnicos de produção, médicos, químicos, psicólogos, etc.).

A antinomia entre promoção da saúde e controle de comportamento foi analisada sobretudo nos Estados Unidos. Esta nasce do próprio conceito de promoção da saúde, que consiste na associação do empenho individual com as ações coletivas, para a educação sanitária à prevenção. Com base nisto muitas empresas nos Estados Unidos começaram a oferecer incentivos financeiros aos trabalhadores que adotassem comportamentos mais saudáveis. Por exemplo, um prêmio para quem parasse de fumar (que teria que ser devolvido caso a pessoa voltasse a fumar); ou um 
prêmio para cada quilograma perdido por um trabalhador obeso, também neste caso reversível; ou também um estímulo para quem desenvolvesse atividade físico-esportiva, pago em centavos ou em dólares, por quilometragem percorrida e o meio empregado: bicicleta, caminhada, natação. Como este tipo de comportamento pode de fato beneficiar a saúde, haveria uma vantagem para os trabalhadores, assim como para a empresa. Esta, perderia menos com a ausência dos trabalhadores devido a doenças e gastaria menos dinheiro com encargos sanitários.

A utilidade não apenas dessas práticas, mas de sua imposição com incentivos financeiros e com métodos mais ou menos coercitivos, pode ser discutida também no plano prático. É quase certo que renunciar ao cigarro beneficia a quase todos; no entanto não é igualmente certo que a perda de peso e a atividade físico-esportiva sejam benéficas para todos. Tais escolhas devem ser realizadas com cautela, personalizadamente, adotadas com critérios seguros porque do contrário podem representar riscos, e, para corrigir um desequilíbrio, pode-se criar outros de natureza física ou psíquica.

Mas as objeções principais são de natureza ética. Estas têm por sua vez, implicaçōes sobre a saúde. Uma, foi exposta com clareza por Allegrante e Sloan em um editorial de Preventive Medicine ${ }^{10}$. Nasce da constatação à qual freqüentemente tendemos "to perceive the world as a just place in which people get what they deserve and deserve what they get". O resultado pode ser este: "If people become ill, we tend to attribute the causes of their illness to them and to their behaviour. In this way, at least psycologically, we are protected against the possibility that we will suffer from the same illnes. Following this logic, it becomes convenient to target health promotion at individuals rather than organizations, since individuals are seen to be the cause of their illness". 
Esta tendência comporta duas consequências. Uma delas é definida como blaming the victim: concentrar a atenção (e a sanção) sobre a vítima, ao invés de concentrá-las sobre as circunstâncias e o problema. Mesmo sendo certo que algumas doenças, por exemplo as cárdio vasculares, são influenciadas por comportamentos pessoais, é entretanto certo que estes estão freqüentemente condicionados ao "status" social e ao nível de instrução. É típico o exemplo do fumo, que tende hoje em dia a estar mais difundido nas classes mais pobres. Como salientou há muito tempo Minkler, é certo que historicamente, a culpa predominante das doenças e dos acidentes tem sido atribuída aos trabalhadores, ao invés de ser atribuída às empresas, mais potentes e imutáveis ${ }^{11}$. Um entendimento equivocado da promoção da saúde pode acentuar esta tendência. A outra consequência é a seguinte: "Workers exposed to carcinogenes in the workplace 'must' be taught not to smoke so as to reduce their risk; hypertensive who work under perpetually stressful conditions must be taught to relax". Em outras palavras, a imposição dos comportamentos considerados mais salubres às pessoas passa a ser considerada uma alternativa menos onerosa para as empresas, quando comparada à adoção de medidas de caráter técnico, organizativo e ambiental.

A conclusão a qual chegam os autores Allegrante e Sloan é a seguinte: "We do not mean to suggest that individuals have no responsability whatsoever in the causal nexus of health: such an assertion would be false and irresponsible. However, blame for lung cancer, for example, cannot be assigned exclusively to an individual who is assaulted with persuasive messages from advertisers or who works with known carcinogens on a daily basis. The use of behaviour-change strategies must be balanced with enlightened practices designed to address organizational-level factors contributing to health risk" ${ }^{12}$. A esta observação podemos agregar outras perguntas que têm implicaçāo ética: quem decide em favor 
de quem, estas estratégias? quem informa e quem é informado? baseadas em que certezas são assumidas as orientações? A última pergunta leva a questões complexas e contraditórias, aqui me limito a mencioná-las: A relação entre noções e preconceitos no conhecimento científico; a possibilidade dos médicos (e em particular dos epidemiólogos) de determinar os comportamentos dos saudáveis; o direito de cada um de escolher o próprio "estilo de vida".

A terceira antinomia, que interessa não só ao trabalho mas também, em geral, à relação homem-ambiente, é aquela que se estabelece entre o risco e o benefício. Essa corresponde a um dilema objetivo, mas pode também ser considerada como uma formulação típica da ética utilitarista, segundo a qual o julgamento a respeito de cada ação humana deve ser feito baseado nas suas conseqüências e não em critérios absolutos de valor; tendo como meta, em particular, a obtenção do máximo de benefício para o maior número de pessoas.

Uma aplicação deste princípio ao trabalho humano é obtida a partir da definição dos MAC (maximun admittable concentration) e também a partir dos TLV (threshold limit value). Estes, em teoria, tendem a estabelecer qual a concentração de uma substância nociva que é inócua para a saúde. Mas, na pratica, baseado no fato de que com o passar do tempo estas taxas tem sido baixadas constantemente, como consequência de pesquisas mais aprofundadas a respeito dos efeitos nocivos de concentraçōes mais baixas, pode-se dizer que estas valem para determinar qual o risco para determinados trabalhadores que é aceitável sem comprometer a continuidade produtiva a qual é considerada vantajosa para a maioria. Sobre este tema desenvolveram-se numerosas controvérsias científicas e jurídicas ${ }^{13}$.

As dificuldades podem ser dramáticas, para os trabalhadores, quando o seu poder é pequeno, quando o estado é inerte, quando as empresas baseiam suas 
atividades na ausência de regras e respeito pela vida humana. No entanto, quando essas condiçōes mudam, os riscos para os trabalhadores ficam atenuados; em alguns casos, podem inclusive tornarem-se inferiores àqueles que qualquer um pode enfrentar na vida fora das atividades do trabalho. Na grande maioria dos casos, todavia, colocam-se problemas éticos extremamente difíceis. Um, é constituído pela não simetria: quase sempre o risco de fato se coloca para alguns sujeitos e o benefício é vantagem para outros. Porém, mesmo se "os outros" são mais numerosos, é difícil justificar, por exemplo o fato de que os trabalhadores que se ocupam com a extração de minérios sejam obrigados a trabalhar em condições particularmente insalubres porque os minérios podem servir a todos ${ }^{14}$. Um outro problema consiste na dificuldade de estabelecer um termo que sirva de comparação para valores que são tudo menos homólogos. Tentou-se assumir como termo de comparação o dinheiro, e avaliar nestas bases a vida humana em risco ou perdida; porém isto pareceu discutível desde o princípio e pouco utilizável no sentido prático, dada a dificuldade de calcular de um lado as vantagens conseguidas por muitos, e de outro o valor de cada vida perdida ou em risco. Este valor , no entanto, é absoluto para o sujeito e é muito variável segundo a condição econômica e cultural de cada sociedade. Não me parece que a ética utilitarista seja adequada para resolver estes problemas.

\section{OS CONFLITOS SOBRE O DIREITO A CONHECER}

O Conhecimento que a pessoa tem em relação a sua própria atividade pode ser considerado como um componente intrínseco da natureza humana, formado através da evolução biológica e, depois, através da ciência. A complexidade do trabalho moderno e a distinção entre trabalho e propriedade privada da empresa 
podem subtrair a imediatez com que esta consciência pode ser alcançada, e constituir em um certo sentido a expropriação de uma faculdade que é natural ao homem e à mulher, sobretudo quando tal expropriação comporta um risco ou um dano psicofísico.

Para se contrapor a essa tendência foi afirmado, primeiro como exigência humana e, depois, com norma jurídica, o direito a conhecer cada aspecto da atividade de trabalho desenvolvida. No que diz respeito à saúde este direito se refere a: a) - A coleta de dados relativos às consequências sanitárias e ambientais da atividade produtiva, seja no que se refere ao sujeito particular, seja no que se refere à coletividade; b) - a disponibilidade e acesso a estes dados da parte de todo aquele que pode ter interesse legítimo em relação a eles.

Em uma nota de V. Navarro ${ }^{15}$ são elencadas algumas dificuldades quanto à aplicação deste direito. Uma das dificuldade é que os trabalhadores devem providenciar eles mesmo a solicitação destas informaçōes, e existem muitas formas explicita ou sutís para impedí-lo. Outra dificuldade é que estes, muitas vezes, parecem não ter motivos para pedir estas informaçōes, pois várias doenças profissionais se manifestam muitos anos após a exposição (por exemplo, os tumores), ou também por que não são específicas (por exemplo, a bronquite crônica e o enfisema), ou também por que podem se manifestar de uma forma insidiosa e subclínica por muitos anos (por exemplo, os efeitos neuro comportamentais do chumbo). $O$ direito a conhecer pode freqüentemente entrar em conflito com o segredo industrial, que é reconhecido pela lei dos diversos tipos de economia competitiva. Na nota, Navarro refere que, nos Estados Unidos, a Suprema Corte tem protegido estes segredos afirmando que a inspeção não pode ser realizada sem que a empresa tenha sido previamente notificada, isto é, dá-se a oportunidade a que seja corrigida ou mascarada uma condição insalubre ou perigosa antes que a visita de inspeção ocorra. 
Mesmo quando, como acontece nos países desenvolvidos onde os trabalhadores conseguiram conquistar leis que the sancionam o direito a esta informação, é escassamente aplicado o dever correspondente, por parte da empresa, de fornecer não somente informaçōes formais (etiquetas, elencos de substâncias usadas, dados ambientais e sanitários), mas também informações imediatamente uteis à finalidade da prevenção. Em alguns países, como a Itália, foi estabelecido e afirmado o direito dos trabalhadores de terem acesso a profissionais de sua própria confiança para evitar o fato de que alguns especialistas reportam-se somente à própria empresa, cujo interesses imediatos podem não ser coincidentes ou mesmo ser contrastantes com aqueles dos trabalhadores.

$A$ isso podemos agregar o fato de que, quando o conhecimento empírico dos próprios trabalhadores ou as pesquisas científicas feitas por especialistas têm revelado a nocividade de determinadas substâncias ou procedimentos, fortes interesses têm tentado esconder os fatos ou dar interpretações elusivas, para não ter que ressarcir aos trabalhadores atingidos ou providenciar transformações produtivas. Muitos casos exemplares foram descritos na literatura científicas.

A exposição ao radônio, no caso dos trabalhadores na extração de minério de urânio e os possíveis efeitos cancerígenos dos herbicidas do tipo clorofenol-acético foram comentados por 0 . Axelson ${ }^{16}$. O caso do amianto foi acuradamente estudado, também através de pesquisas de arquivo, por Lilienfeld e Engin ${ }^{17}$. A partir dos conhecimentos a respeito da pneumoconiose e dos tumores causados por essa condição, resultou que os dois médicos de empresa que individualizaram tais patologias, respectivamente Lanza e Gardner, não tiveram por muito tempo a possibilidade de divulgar os resultados de suas próprias pesquisas. Aquelas sobre possíveis efeitos cancerígenos do amianto tinham sido iniciadas em $1936 \mathrm{com}$ um protocolo de colaboração entre a empresa produtora e o Saranac Laboratory, no qual 
está escrito: "The results obtained will be considered the property of those who are advancing the required funds, who will be determined whether, to what extent, and in what manner they shall be made public".

Estando claro que estes casos não tem a mínima pertinência no que diz respeito ao segredo industrial, que serve apenas para impedir a concorrência ilícita, colocam-se dois problemas éticos e jurídicos. Um, diz respeito ao princípio ético fundamental da ciência, que é a sua liberdade: liberdade de pesquisa mas, também, liberdade de comunicação do conhecimento, sem o que o cientista torna-se um homem incompleto, cessa de existir uma "comunidade científica" e a própria ciência torna-se obstaculizada no seu progresso. O outro problema pode ser formulado com uma pergunta: É justo que informaçōes que poderiam evitar doenças e a morte de pessoas expostas a um risco sejam sequestradas, se tornem propriedade privada de quem possa ter interesse (para não pagar prêmios de seguridade ou ressarcimento) em manter a condição de insalubridade?

Por outro lado, mesmo sem a assinatura de protocolos particulares (como aquele do amianto, que de forma singular é adotado hoje em dia nas relações entre industrias e universidades) este seqüestro de informações vitais é frequente na prática. Quando, por exemplo, se verificou em Seveso, norte da Itália, a explosão do reator químico da fábrica ICMESA, e uma densa nuvem contendo dioxina se difundiu na zona, a partir da pesquisa que foi realizada após o acidente resultou que o nível de informação sobre o problema, entre as pessoas interessadas, era inversamente proporcional ao risco. Os dirigentes da multinacional Hoffman-La Roche à qual pertence a ICMESA, com sede na Suíça, tinham total conhecimento dos detalhes, tanto é verdade que a fábrica havia sido instalada para além dos Alpes, já em território italiano; os trabalhadores e os cidadãos daquela região, ao invés, não sabiam nem mesmo que existia uma substância altamente tóxica chamada dioxina. Em uma escala 
muito mais ampla, desequilíbrios análogos ou mais graves ainda existem nas relações de conhecimento entre o norte e o sul do mundo. $\mathrm{O}$ amianto, por exemplo, continua a ser extraído, produzido e usado em muitos países, sem que os trabalhadores e a população conheçam o que já se sabe a respeito da nocividade deste produto.

Na verificação e na transmissão da informação, o papel de maior conflito pode ser aquele do médico do trabalho. Até a relação corriqueira médico-paciente pode estar condicionada pela possibilidade de maior abertura ou fechamento da informação na empresa. Quais as informações que dizem respeito ao trabalhador o médico pode transmitir à empresa, e quais informações que dizem respeito à empresa ele deve transmitir ao trabalhador? Os dilemas éticos e os conflitos profissionais desta figura peculiar da medicina são um tema muito discutido na literatura bioética e médico legal.

Menos discutidos, mas cada vez mais urgentes e prementes, são os conflitos éticos que dizem respeito aos pesquisadores: seja para quem faz experiências biológicas sobre os teores tóxicos, seja para quem estuda no campo da epidemiologia. Encontrado e definido o teor nocivo de uma substância ou de um procedimento a quem e como comunicar? s vezes cala-se por conveniência; outras vezes, dada a incerteza que carateriza as pesquisa biológicas, porem mais freqüentemente a pesquisa epidemiológica, prevalece a tentação de "proteger" os trabalhadores de preocupações não ainda completamente comprovadas. Até que ponto este é um álibi decorrente da desconfiança acerca da capacidade dos trabalhadores de compreenderem e avaliarem os dados científicos?

Pode-se afirmar, para concluir este ponto, que o conceito de "segredo profissional" é válido quando a divulgaçāo de uma noticia que diz respeito ao trabalhador pode prejudicá-lo. Porém, ao contrário disto, quando podem derivar 
informaçōes sobre atividades nocivas ou de risco, deveria enfatizar-se o conceito de "divulgação obrigatória" como norma deontológica a ser considerada quanto ao segredo, seja para os médicos seja para os pesquisadores. É bastante precisa, exatamente como ponte entre estes dois deveres, a formulação do artigo 105 do Código de Ética Médica do Brasil, o qual proíbe "to reveal confidential information obtained during medical examination of workers, even when requested to do so by managers of enterprises or institutions, unless keeping silent jeopardises the health of the employees or the community". ${ }^{18}$

\section{OS CONFLITOS ENTRE PRODUÇÃO E AMBIENTE, ENTRE TRABALHADORES E POPULAÇÃO}

Desde a revolução industrial, até poucos decênios atrás, apenas alguns poucos pensadores e políticos, isolados e não ouvidos, tinham alertado para os perigos da contaminação ambiental e, em geral, a respeito da alteração da biosfera. A opinião que prevalecia, quando tais fenômenos se manifestavam, era que este era um preço inevitável a ser pago pelo progresso. As doenças mais graves tinham sido, por algum tempo, aquelas de origem microbiológica, e a respeito dessas havia sido primeiro levantada a hipótese e, depois, demonstrada a transmissão da infecção, o contágio direto ou mediato através de artrópodes, alimentos, o ar e a água. Não era percebida a existência de um outro tipo de contágio, que consistia na difusão de fatores patogênicos desde a fábrica para o ambiente externo, do trabalho ao consumo, mediante os produtos (amianto, por exemplo), mediante a emissão de elementos de contaminação no ar, na água e no terreno (e destes para os alimentos, como no caso dos pesticidas), assim como também mediante modelos de organização da vida, como 
o consumo de energia e o ritmo trabalho-repouso, que influenciam no equilíbrio seja do ambiente natural, seja da saúde humana.

No plano histórico, seria interessante analisar os motivos pelos quais a percepção deste tipo de contaminação foi adiada desta maneira, em comparação com o contágio por micróbios, apesar de fato deste último ser devido a seres vivos que permaneceram por muito tempo invisíveis, enquanto o outro tipo, em muitos casos, era diretamente acessivel com o simples uso natural de um ou mais dos cinco sentidos humanos. Uma das razōes pode ser que as vantagens derivadas do progresso industrial foram muito relevantes, de modo a ofuscar os seus danos; mas também neste caso ( que diz respeito a relação entre riscos e benefícios) o julgamento foi provavelmente influenciado por uma assimetria cultural: quem pode usufruir das vantagens provavelmente teve uma voz mais forte do que aqueles que tiveram que assumir os danos ou dos que os assumiriam no futuro.

Uma outra análise, que diz respeito ao presente, consiste em avaliar as razões pelas quais os dois movimentos ambientalistas mais importantes das últimas décadas, aquele pela saúde dos trabalhadores e aquele pela proteção da natureza, estiveram tão longe um do outro e às vezes conflitivos entre eles. Isto pareceu particularmente evidente na Itália, onde ambos os movimentos foram muito vastos e incisivos.

Enquanto, nos anos 60 e 70, havia emergido com vigor o tema do ambiente de trabalho, que tinha unificado forças sindicais científicas e profissionais, mas também que havia criado um senso moral comum no país, nos anos 80 emergiram situações diferentes. Em algumas fábricas, sobretudo químicas, como a ACNA de Cengio, a FARMOPLANT de Massa, a ENICHEM de Manfredonia, a SOLVAY de Rosignano, a exigência dos trabalhadores por manter a atividade produtiva se contrapôs ao direito 
da população vizinha a viver em um ambiente não contaminado. O confronto foi áspero, em alguns casos houve inclusive duas manifestações simultâneas frente ao parlamento da nação: uma dos cidadãos, que pediam o fechamento da fábrica, e a outra dos trabalhadores que solicitavam a continuidade e o fortalecimento da produção. As soluções adotadas (a FARMOPLANT foi fechada, a SOLVAY renunciou ao desenvolvimento de novos projetos de instalaçōes, a ENICHEM e a ACNA continuaram produzindo e poluindo um pouco menos) não foram certamente satisfatórias. Isto ocorreu devido à falta de preparo científico, à inércia e oscilação das instituiçōes, à carência de leis adequadas, ao fechamento de associações (sejam sindicais, sejam ambientalistas) e a outras razões. Mas deve-se sobretudo ao fato de que tais situaçōes são administráveis somente se for projetada a atividade produtiva e a previsāo de seus impactos, ao passo que, se isto não acontece, os gastos acabam tornando-se insuportáveis: os gastos por conta da saúde, da natureza, da economia, mas também do dilaceramento social e dos dramas pessoais. Em muitos dos exemplos citados verificou-se por exemplo a contraposição entre os trabalhadores e suas próprias famílias.

O problema ético, aquele do conflito entre os legítimos interesses dos trabalhadores e os da população, raramente pode ser resolvido a posteriori, porque isto significaria sacrificar a uns ou a outros; requer, como já acentuamos, que o sistema de valores humanos e naturais seja incorporado ainda na fase de planejamento e de previsão e confrontado com o sistema das vantagens possíveis de obter na esfera da produção e do consumo. Levando em consideração naturalmente o fato que, quando não há produção, a falta de trabalho e a pobreza provocam também doenças $e$ degradam 0 ambiente.

Esta orientação do planejamento e das previsōes poderia ser favorecida por uma aproximação dos dois movimentos, que estiveram até agora distantes e, em 
alguns momentos, se opondo um a outro. Visando este objetivo, segundo Epelman ${ }^{19}$ , é necessário superar preconceitos recíprocos: "Por un lado, los trajadores muchas veces piensan que el movimiento ambientalista, con su acción en contra de la contaminación, está amenazando sus fuentes de trabajo. Por otra parte, los ambientalistas piensan que al movimiento sindical solo le interessa luchar por reivindicaciones economicas". Não creio que estes sejam apenas preconceitos: em muitos casos trata-se de pós julgamentos que são decorrentes, em ambos os casos, de experiências reais. Mas é necessário enfatizar a exigência de uma concessão e de uma orientaçāo unitária que pode basear-se em substanciais coincidências de interesses, ou seja, em raízes objetivas, hoje ofuscadas pelas contradiçōes criadas pelo tipo de desenvolvimento que vem ocorrendo e que se afirmou como dominante.

Até o momento falei de conflitos e problemas éticos que se manifestam no interior de muitos países. Junto com estes, estão emergindo três temas mais complexos que me limito a enunciar.

O primeiro diz respeito ao espaço mundial. Frente à norma e a movimentos que tendem a regulamentar, nos países desenvolvidos, o impacto ambiental e sanitário da atividade industrial, está se manifestando uma tendência crescente por parte das empresas multinacionais, e também por parte de empresas menores, a transferir as suas atividades para países pobres. A exportação se refere também a produtos proibidos, como amianto e corantes reconhecidos como cancerígenos e, ainda, aos resíduos tóxicos das fábricas. Criam-se, assim, dois sistemas normativos correspondentes a dois tipos diversos de valores do trabalho humano, da vida e do ambiente $^{20}$. Há algum tempo a OMS e a agência internacional para pesquisa do câncer (IARC) têm chamado a atenção sobre estes argumentos, sem que se tenha verificado uma inversão significativa desta tendência. 
O segundo diz respeito ao tempo da geração, isto é, à influência dos nossos atos para com as gerações humanas futuras e para com o equilíbrio global da biosfera. A dificuldade de assimilar este tema à existência de outros direitos foi colocada em evidência por Jonas. Ele escreveu que o esquema segundo o qual "uma vez estabelecidos certos direitos a isto segue-se o meu dever de respeitá-los e possivelmente de promovê-los" não funciona neste caso: de fato "o que não existe não levanta nenhuma exigência e não pode nem mesmo sofrer nenhuma violação dos seus direitos" ${ }^{\prime 21}$. Porém ele afirmou que o problema deve ser igualmente enfrentado no plano ético, uma vez que surge "uma responsabilidade metafísica em si e por si, desde o momento no qual o homem tornou-se um perigo, não somente para si mesmo, mas para toda biosfera", em consequência "o interesse do homem coincide no sentido mais sublime com o restante da vida enquanto sua morada cósmica". Pode-se, portanto, recorrer "ao conceito guia de dever para com o homem, sem por causa disto cair em uma visão reducionista e antropocêntrica"22 . Pode-se avaliar o quanto estão distantes destas idéias o método e a substância da politica, na sua prática cotidiana. A própria democracia, enquanto poder dos cidadãos existentes e eleitores, para ser idônea na interpretação desta responsabilidade, deve dar voz àqueles que não podem exprimir-se: aqueles que ainda não nasceram, que constituem maioria muito superior em comparação com os humanos viventes, e às outras espécies que são contemporâneas e, convivem com a nossa.

O terceiro tema diz respeito ao dever de agir na incerteza científica. Em muitos casos, de fato, a consequência sanitária e ambiental da atividade produtiva está ainda além do conhecimento científico. Porém, pode ocorrer em alguns casos que, mesmo não tendo certeza de um dano, se tenha uma outra certeza: que, se não se intervier tempestivamente, as ações reparadoras serão tardias e o dano se tornará irreversível. Os exemplos mais evidentes são aqueles das variações climáticas em 
escala global causadas pela emissão de anidrido carbônico, e da destruição do "camada de ozônio"; e existem também casos relativos a substâncias suspeitas como cancerígenas, presentes no trabalho e no ambiente. $O$ princípio médico im dubium abstine, que tem a finalidade de evitar, em caso de dúvida, qualquer ato que possa ser nocivo ao paciente, deveria valer como principio ético que guiasse o governos em cada ação e omissão que possa causar danos coletivos.

\section{CONFLITOS ENTRE TRABALHADORES}

Estes podem surgir quando um ou mais trabalhadores estão afetados por doenças contagiosas ou mentais, ou por um handicap psicosensorial, ou têm comportamentos (como pode acontecer em alguns casos de toxico dependência) que podem causar danos aos demais. Isto pode acontecer de diferentes maneiras: a transmissão direta de infecçōes, o "contágio" de hábitos insalubres para outros trabalhadores e o aumento de riscos de acidentes. Estes temas não são novos, mas nos últimos anos a controvérsia se acentua por dois motivos: a presença nos locais de trabalho de pessoas soropositivas para HIV, e o reconhecimento dos efeitos patogênicos do "fumo passivo".

Estes conflitos dizem respeito a valores e interesses os quais têm, cada um deles, uma dignidade moral própria. Por um lado há o direito de todas as pessoas ao trabalho, e isto assume uma ênfase específica quando o trabalho por si só pode significar uma função de apoio e de terapia para pessoas frágeis e lábeis: por exemplo doentes mentais, deficientes, tóxico dependentes. Nestes casos, a exclusão e a segregação podem ser agravantes. Por outro lado, há o direito dos trabalhadores 
"normais" ou "saudáveis" a não adquirirem danos, e a não serem expostos a riscos adicionais devido às condições e ao comportamento de outros trabalhadores, inclusive pode-se acrescentar que, mesmo em casos raros, tais condições ou comportamentos podem constituir perigo para outras pessoas, por exemplo, para passageiros de trem e aeronaves. Assim, se confrontam: de um lado a solidariedade para aqueles que sofrem e a tolerância (ou melhor a aceitação) para com aqueles que são desviantes, de outro lado a segurança.

Este tipo de conflito não pode ser negado, em alguns casos são efetivamente necessárias medidas de restrição e até mesmo de exclusão para as pessoas que, mesmo sem culpa, são efetivamente perigosas. No entanto, a maioria das vezes a questão torna-se mais aguda devido aos preconceitos que tendem a agigantar o risco, e até mesmo a inventá-lo onde não existe, como acontece, na maioria dos casos que dizem respeito aos doentes mentais e aos soropositivos HIV. A estigmatização de algumas doenças e de alguns comportamentos em relação a outros (somente agora, por exemplo, o protesto das trabalhadoras fez emergir o tema da violência e do assédio sexual por parte dos trabalhadores e dos dirigentes das empresas do sexo masculino) freqüentemente altera as informaçōes objetivas e cria obstáculos a uma síntese, que quase sempre é possível, entre os valores de solidariedade e a segurança.

É justo reconhecer, com vantagens para a ltália, que estas áreas de conflito entre os trabalhadores foram bastantes circunscritas. Assim, foram realizadas experiências exemplares de integração ao trabalho de deficientes físicos e psicosensoriais, de doentes mentais e também de tóxico dependentes. Os fatores que influenciaram positivamente são sobretudo: o senso de solidariedade que, quando oportunamente solicitado e acompanhado pela explicação justa e necessária, sempre se manifestou entre os trabalhadores; o comportamento aberto de muitos 
empreendedores, e as leis aprovadas pelo parlamento. Entre essas é particularmente significativa a lei a respeito da AIDS, a qual prescreve a aceitação dos soropositivos por parte das empresas e proíbe que a soropositividade seja considerada motivo para exclusão do trabalho, a não ser em pouquíssimas atividades que efetivamente constituem um risco para outros trabalhadores ou para os cidadãos. Problemas análogos surgem com a tentativa de submeter os trabalhadores ao drug-testing. Uma outra situação que nos Estados Unidos, mas também em outros países, já causou controvérsias mais ou menos graves é a presença de fumantes no trabalho, devido aos riscos e ao incômodo acarretado pelo "fumo passivo", mas este é um problema de solução mais fácil.

Um problema ainda nāo resolvido para o qual vê-se poucos melhoramentos é aquele da relação com os trabalhadores imigrantes. Mesmo se os sindicatos algumas vezes se empenharam por tutelar esses trabalhadores imigrantes, permanece o fato de que estes desenvolvem, quase sempre, os trabalhos mais pesados e nocivos, têm uma retribuição financeira menor, gozam de pouca proteção sanitária e previdenciária, vivem em habitações precárias, correm o risco de serem despedidos e mesmo expulsos do país. Condiçōes similares existem em outros países da Europa Ocidental e nos Estados Unidos. Mas a Itália, que é o único entre estes a ter vivido, entre o século $X I X$ e o século $X X$, a experiência oposta, ou seja a da emigração em massa, agora que é sede de imigração deveria manifestar mais sensibilidade do que outros países manifestam. Os temas éticos que surgem nesse campo são análogos àqueles já abordados a propósito da exportação de produtos da produção e de resíduos tóxicos e nocivos: também nesse caso estamos diante de dois tipos diferentes de valores de trabalho e da vida com base étnica e geográfica. 


\section{CONFLITOS ENTRE TRABALHO, SAÚDE REPRODUTIVA E REPRODUÇÃO DA VIDA HUMANA}

Como introdução a este ponto, pode-se lembrar a já citada afirmação da Pacem in Terris, que prevê para as mulheres uma condição peculiar: "o direito a condiçōes de trabalho conciliáveis com as suas exigências e com os seus deveres de esposa e mãe". As intenções são claras e elogiáveis; mas esta formulação (ao contrário de muitas outras que estão contidas na mesma encíclica, que são antes precursoras), fala somente de exigências e deveres "de esposa e de mãe", e não se refere a análogas exigências e deveres "de esposo e de pai".

Não pretendo discutir aqui a função que a Igreja Católica atribui tradicionalmente à mulher. Me deterei, no fato que, enquanto no passado se colocava ênfase somente nas conseqüências prejudiciais para os nascituros derivadas do trabalho pesado e nocivo da mãe, as pesquisa epidemiológicas e toxicológicas recentes têm mostrado que os danos para a função reprodutiva, a fertilidade e o patrimônio genético podem derivar, em igual medida, do sexo masculino. Este tema foi particularmente desenvolvido por I. Figà Talamanca ${ }^{23}$, resumirei portanto as suas pesquisas e as suas considerações.

Várias manifestaçōes patológicas para a saúde reprodutiva derivam da exposição a condiçōes de trabalho que normalmente não causam danos a outros órgãos e funções. No período anterior à concepção, por exemplo, representam riscos a radiação ionizante, os metais pesados, alguns pesticidas como o diclorobromopropano (DBCP), que é aceito como causador de dano para espermatogênese e de esterilidade masculina. Durante a gestação, provocam às vezes a morte pré-natal e o aborto os gases anestésicos, as irradiaçōes ionizantes e outros 
agentes físicos e químicos presentes nos ambientes de trabalho. Tais fatores, além de representar riscos de nascimentos prematuros, em alguns casos podem levar a defeitos congênitos.

No plano ético toda a atenção tem se concentrado, até o momento, no conflito entre o direito da mulher ao trabalho e o direito da criança a nascer. ${ }^{24}$ Conseqüentemente, muitas indústrias nos Estados Unidos têm adotado uma política de "tutela da maternidade" que obriga as mulheres em idade fértil a serem transferidas para "ambiente salubre"; quando isso não se revela possivel, muitas são simplesmente demitidas. $\mathrm{O}$ argumento sugerido, que se quer de tal modo "privilegiar a saúde das futuras geraçōes", nāo resiste à análise científica por três motivos.

O primeiro é que a pesquisa, por exemplo aquela sobre os efeitos reprodutivos do chumbo, tem demonstrado que é tão perigoso para a reprodução expor àquele metal um homem jovem, quanto uma mulher ${ }^{25}$; há também grandes evidências científicas sobre o fato de que a exposição paterna à radiação está associada à leucemia, mas até agora ninguém propôs excluir os homens dos trabalhos que expõe a este risco para proteger os seus eventuais filhos. O segundo é que quase nunca é oferecida a possibilidade de escolha entre um trabalho e outro, mas entre 0 trabalho e o desemprego, uma condição na qual os riscos para os filhos são bem maiores. O terceiro é que a tendência a resolver os conflitos éticos e práticos distanciando dos riscos do trabalho os sujeitos mais suscetíveis, sejam eles homens ou mulheres, jovens ou anciãos, fortes ou vulneráveis, além de ser uma prática discriminatória é também um obstáculo para a prevenção seja para estes ou para todos. De fato, os mesmos fatores nocivos atingem também os trabalhadores considerados "normais", mesmo que seja com uma frequência comparativamente menor; porém, em termos de taxas absolutas, o dano é de toda forma alto. Em outras palavras, aqueles que estão mais expostos ao risco são como sentinelas de um 
presídio: se estes são afastados, o assalto é facilitado e a vida de todos é colocada em perigo.

A escolha de afastar as mulheres do trabalho, baseada na política da "tutela do feto", continua todavia a ser aplicada, às vezes com métodos bárbaros. A Americam Cyanamid Company, um grande complexo industrial químico dos Estados Unidos, decretou, por exemplo a exclusão das repartiçōes em que ocorre o risco de exposição ao chumbo das mulheres que não são estéreis ou dispostas a se esterilizarem, oferecendo gratuitamente a intervenção cirúrgica e propondo, caso as mulheres não aceitem, a transferência para outro trabalho ${ }^{26}$. Somente sete, entre as trinta mulheres que deveriam ser afastadas, porém, conseguiram outro emprego; muitas foram demitidas e cinco escolheram a esterilização "voluntária" para poder manter o trabalho. A dolorosa escolha entre os dois valores em conflito, o trabalho e a maternidade, foi aparentemente remetida para a decisão das próprias mulheres, mas na realidade foi realizada pela empresa que se negou a modificar as condições nocivas existentes no ciclo produtivo. Outros métodos, ainda mais graves, foram identificados em países sub-desenvolvidos. No Sri-Lanka, por exemplo, foi imposto às trabalhadoras em idade fértil submeter-se a um teste obrigatório de gravidez e àquelas que resultaram positivas foi oferecido, mas na realidade foi imposto, recorrer à curetagem para abortar. $^{27}$

Existem, porém, alternativas entre a esterilização mais ou menos coercitiva e a perda do trabalho. A principal é a prevenção ambiental, válida para todos. As demais soluções apresentam vantagens e desvantagens. Na Itália e em outros países desenvolvidos, as leis prevêm, por exemplo, o afastamento do trabalho (acompanhado pela proibição de demissão) das mulheres nos últimos meses de gravidez e nos primeiros meses de puerpério. Porém, agora sabe-se que os danos mais graves ocorrem nas fases mais precoces da gravidez, freqüentemente antes mesmo da 
gravidez ser reconhecida pela mulher; a legislação portanto deve ser atualizada. Se levarmos em consideração que o dano para aquele que está para nascer pode derivar de causas maternas ou causas paternas, parece difícil que isso possa ser resolvido com medidas legislativas ou com controles de tipo pessoal, por exemplo sobre atividade sexual conjugal, e também extra conjugal, de todos os trabalhadores homens que sejam expostos a riscos no trabalho.

De qualquer maneira, é indispensável que qualquer um que seja chamado a decidir um conflito desta natureza tão difícil, seja ele um legislador, um sindicalista ou um trabalhador ou uma trabalhadora, que tenha acesso às informaçóes científicas em termos objetivos e possa orientar-se em bases dos fatos e não baseado em preconceitos para assumir com plena liberdade as próprias decisōes.

\section{CONCLUSÕES}

Compreendo que a escolha de tratar o tema através do agrupamento dos conflitos pode suscitar objeçōes, mesmo porque teria sido possível percorrer uma outra estrada. Por exemplo, seguir um percurso histórico em relação à evolução tecnológica ou às orientações éticas, as quais são bastante mudadas desde o tempo da escravidão até a revolução industrial, sobretudo desde quando os trabalhadores apareceram na cena afirmando direitos próprios. Ou mesmo, assumir como um fio condutor alguns conceitos típicos da relação entre saúde e trabalho, como o risco e a relação custo-benefício. Ou ainda, examinar como este tema tem sido enfrentado pelas várias correntes da bioética. Preferi partir dos conflitos porque estes existem, porque mesmo se algumas vezes foram interpretados de modo ideológico, dizem 
respeito a interesses e pessoas que representam valores legítimos mas freqüentemente divergentes; porque, enfim,o único modo de superar os conflitos é reconhecê-los.

Freqüentemente esses têm como fundamento uma diversidade de conhecimentos e um desequilíbrio de poder; um poder que se exprime através da materialidade corpórea e da dignidade humana condicionando-a, colocando-a em risco, minando às vezes a saúde e subtraindo anos e qualidade à vida. A única referência moral segura pode ser, portanto, a corporalidade humana e a dignidade de cada pessoa. Entretanto, é fácil escorregar, mesmo na deontologia profissional, para a proteção dos interesses mais fortes, que podem coincidir mas também colidir com aqueles da coletividade.

É interessante, a esse respeito, a pesquisa realizada nos Estados Unidos sobre as orientações éticas dos médicos do trabalho28. Emergiu, como dado essencial, o confronto entre duas linhas: a manutençāo da própria identidade deontológica, que, mesmo levando em consideração cada um dos outros interesses e valores, coloca no centro o trabalhador singular; ou então, tomar como critério-guia aquele do utilitarismo teleológico. O utilitarismo, porém, não leva em consideração, do ponto de vista do trabalho, a minoria daqueles que estão expostos a riscos particulares, porque está orientado em função de um interesse às vezes verdadeiro, mas muitas vezes apenas presumido, da maioria; nem considera, do ponto de vista do equilíbrio ambiental, a maioria das gerações, constituída pelos pósteros, os quais serão (salvo a eventualidade de uma catástrofe) muito mais numerosos que os atuais viventes.

Ao invés disso, assumir como referência a corporalidade e a dignidade humana dos trabalhadores singulares pode, ao contrário, estimular transformaçōes 
produtivas (materiais, processos, organização do trabalho, produto) que sejam mais favoráveis ao homem e à mulher e respeitem mais a natureza. Não se pode por certo presumir que, desta maneira, os conflitos que elenquei desapareçam, mas em muitos casos podem ser evitados, ou atenuados em dimensão e em gravidade.

Isto, no entanto, é o que aconteceu nos lugares e nas fases mais positivas da relação entre saúde e trabalho. O conflito entre os trabalhadores e a empresa tornou-se menos dramático quando foram criados entre os dois antagonistas um maior equilíbrio de poder. Os conflitos a respeito da informação foram freqüentemente resolvidos, quando a todos foi garantido o acesso a notícias úteis aos fins preventivos e quando se manteve a confidencialidade dos dados pessoais dos trabalhadores singulares. O conflito entre os trabalhadores e a população, entre produção e ambiente permanecem sem resolução, nem mesmo quando foi avaliado preventivamente o impacto sanitário e ambiental de novas instalações e novos empreendimentos. Os conflitos entre trabalhadores "perigosos" e trabalhadores "normais" reduziram-se a poucos casos quando a natureza do risco foi avaliada com base em informações objetivas ao invés de preconceitos; e se transformaram num desenvolvimento comum das duas partes, da ética e da prática, quando o espírito de integração prevaleceu sobre a victim blaming e sobre a segregação. Os conflitos entre trabalho e reprodução da vida humana se reduziram ao mínimo, quando as regras de prevenção ambiental substituíram a demissão de mulheres em idade fértil.

Certamente essas experiências não podem valer, de per si, para dirimir conflitos entre valores e interesses que são em alguns casos inconciliáveis, nem orientar no plano teórico escolhas que são contraditórias e difíceis. Quanto mais a reflexão bioética se conjugar com o desenvolvimento histórico da vida cotidiana, mais esta encontrará no próprio homem, neste caso o trabalhador e a trabalhadora considerados como indivíduos e como sujeitos, uma referência segura. 


\section{REFERÊNCIAS}

1 G. Rossi: Si Invoca l'etica quando è in crisi il diritto, "Corrierre della Sera", 26 maggio 1987.

2 International Labour Office: World Labour Report 1993, Geneva pp. 1-2 e 9-18.

3 Já por mim assinalada e comentada com outros exemplos, no capítulo Bioética cotidiana e bioética de fronteira do livro Questōes de vida, HUCITEC, São Paulo, 1993.

4 "The New York Time Magazine", 13 de setembro 1970, p. 32. Cit. por W.R. Lee: "Some ethical problems of hazardous substances in the working environment, "British Journal of Industrial Medicine", 1977, 34 274-280.

5 S. Rodotà: Test genetici per lavatore "La Repubblica", 18 julho 1992.

6 J. Harris: Le biotecnologie nel 2000. Wonderwoman e Superman "Bioetica", n. 1, 1992, p.32.

7 OTA, US Congress: The role of gene testing in the prevention of occupational diseases, 1983 , e M. Cummings: Human heredity: Principles and issues, West Publishing Co, St. Paul 1988, p. 406. Cit. por S. Nespor, A. Santosuosso, R. Satolli: Vita, morte e miracoli, Feltrinelli, Milano 1992, pp. 97-112 e nota a p. 112

8 J. Harris, cit

9 Para a reconstrução deste movimento cf. M.L. Righi: Le lotte per l'ambiente di lavoro dal dopoguerra ad oggi, in "Studi storici", n. 2/3, 1992, pp. 619-652. Cfr. também G. Berlinguer: La salute nelle fabbriche, nuova edizione ampliata, De Donato, Bari 1977 (prima edizione 1969).

10 J.P. Allegrante e R.P. Sloan: Ethical Dilemmas in Workplace Health Promotion, "Preventive Medicine" 15, 313-320, 1986

11 M. Minkler: Ethical issues in community organization, cit. in Allegrante e Sloan, p. 315 12 Cit., pp. 315-316

13Ver,p. ex. W.J. Curran, SM Hyg e L.I. Boden: Ocupational Health Values in the supreme Court: Cost-Benefit Analysis, "American Journal of Public Health", November 1981, vol. 71, n. 11, pp. 1264-1265

14W.R. Lee:Some ethical problems of hazardous substances in the working evironment, "British Journal of Occupation Medicine", 1977, 34, 274-280 
15 V. Navarro: An international study on ethics and values in occupational medicine. Comunicação pessoal, versão preliminar de projeto de pesquisa, março 1992

16 O. Axelson: Etica, politica interpretazione dell'evidenza scientifica dei rischi per la salute dovuti a esposizioni ambientali e professionali, "Epidemiologia e prevenzione", n. 42, 1990, pp. 8-11

17 D.E. Lilienfeld e M.S. Engin: The Silence: the Asbestos Industry and early Occupational Research - A Case Study, "American Journal of Public Health", June 1991, vol. 81, n. 6, pp. 791-800.

18 Citado por H. Pereira Dias: Bioethics: Implications for Medical Practice and Deontological and Legal Standards in Brazil, in "Bioethics, Issues and Perspectives", S. Scholle Connor e H.L. Fuenzalida-Puelma editors, Pan_american Health Organization, 1990, p. 138.

19 M. Epelman: Sindicalismo y medio ambiente en Argentina, mimeo janeiro, 1992.

20 P. Comba: $\Perp$ rischio ambientale e la salvaguardia della vita umana: aspetti etici "Protestantesimo", XLVI, 4/1991, pp. 287-300.

21 H. Jonas: ॥l principio responsabilità. Un ' etica per la civiltà tecnologica, Einaudi, Torino 1990, p. 49. 22 Cit, p. 175.

23 I. Figà Talamanca e G. Berlinguer: Problemi bioetici in medicina del lavoro, relazione al congresso di Medicina del lavoro, Torino 1992.

24 Cfr. por ex. M. Lavine: Ethical and policy problems, in "Environment" 1982, 24 (5), 26-38.

25 M. E. Becker: Can employers exclude woman to protect children?, "Journal of the American Medical Association", 1990, 246 (16): 2113-2117.

26 A. Hricko: Social policy considerations of occupational health standards: the example of lead and reproductive effects, "Preventive Medicine", 1978, 7: 394-406, eW.J. Curran: Danger for pregnant women in the work place, The New England Journal of Medicine", Jan. 17 1985, pp. 164-165.

27 I. Figà Talamanca: Zone industriali libere e adolescenti sfruttate, "Salute umana", n. 107, 1990.

28 P.W. Brandt-Rauf: Ethical conflict in the practice of occupational medicine, "British Journal of Industrial Medicine", 1989, 46, 63-66. 